policy is a set of principles which affirm the legal and human rights of users of mental health services - principles which are to be found in many a patients' charter, in the Mental Health Act code of practice and even, increasingly, in the operational policies of NHS trust services. It is very worrying that such principles could be deemed anti-medical establishment and, worse, destructive.

Dr Gamble leaves his most outrageous accusation - of local advocates' "tacit encouragement of violence against staff" - till last. We are mystified as to why, if there have been genuine concerns of such a serious nature about employees in our service, no one has brought them directly to our attention.

We are very sorry that Dr Gamble's 'exposure' to advocacy during his training has made such a negative impact on him but we also believe that the conclusions he draws from his limited experience are unwarranted. Of course there are sometimes problems in the practice of advocacy (just as there are sometimes problems in the practice of psychiatry), but we would expect any important concerns about our service to be discussed with us frankly and respectfully. We sincerely hope that other psychiatrists are more inclined to share the stand of Thomas \& Bracken (Psychiatric Bulletin, June 1999, 23, 329) that psychiatry needs to move 'away from a negative antipsychiatry view of advocacy to a more constructive engagement'.

Richard Smith, Director, Val Ford, Service Manager, Mind inTower Hamlets, 13 Whitethorn Street, London E3 4DA

Sir: We are grateful to Dr Gamble for his letter (Psychiatric Bulletin, September 1999, 23, 569-570) which simply helps to reinforce the purpose of our original article (Thomas \& Bracken, Psychiatric Bulletin, June 1999, 23, 327-329). Dr Gamble's attitudes towards advocacy demonstrate how important it is that the College makes exposure to local advocates and advocacy services a mandatory requirement for all training schemes for the Membership Examination.

Phil Thomas, Consultant Psychiatrist, Pat Bracken Consultant Psychiatrist, Bradford Community HealthTrust and Senior Research Fellows, Bradford University, Bradford HomeTreatment Service, Edmund Street Clinic, 26 Edmund Street, Bradford BD5 0BJ

\section{Consent of 16- and 17-year olds to admission and treatment}

Sir: Parkin (Psychiatric Bulletin, October 1999, 23, 587-589) is correct in stating that current guidance on consent to treatment as set out in the 1999 Code of Practice "remains potentially confusing and is inconsistent with good practice". Although the Mental Health Act 1983 (MHA) has built into it greater protection for patients' rights regarding consent to treatment, if the child is not under a section of the MHA, the compulsory regulations of the MHA do not apply. For the child in the community or admitted 'informally', that is, not under the MHA, the new Code of Practice (Department of Health \& Welsh Office, 1999) seems to be undermining the competent child's rights regarding consent to treatment. In doing so it is following the judicial paternalism of recent case law, which seems to subjugate one of the Code's guiding principles, that is, that people to whom the MHA applies should "be treated and cared for in such a way as to promote to the greatest practicable degree their self-determination and personal responsibility, consistent with their own needs and wishes", in favour of other 'best interests', which may be assumed to be a professional (whether judicial or medical) understanding of their physical or mental well-being. This makes the new Code internally inconsistent as well as "inconsistent with good practice". I echo Parkin's call to the Mental Health Act Commission to investigate such inconsistencies.

\section{Reference}

DEPARTMENT OF HEALTH \& WELSH OFFICE (1999) Code of Practice to the Mental Health Act 1983 (Pursuant to Section 118 of the Act). London: The Stationary Office.

Moli Paul, Senior Registrar in Child and Adolescent Psychiatry, Parkview Clinic, 60 Queensbridge Road, Birmingham B13 8QE

\section{Use of the Mental Health Act to treat compliant mentally incapacitated patients with electroconvulsive therapy}

Sir: Having recently been involved in a difficult clinical dilemma, we have had it brought to our attention that our usual practice and what we believed to be the common practice of psychiatrists throughout the country is in fact contrary to the Code of Practice.

The dilemma involved the need to resort to the use of the Mental Health Act 1983 (MHA) when wanting to treat a compliant mentally incapacitated patient (due to mutism secondary to severe psychotic depression) with electroconvulsive therapy (ECT). Nobody would dispute the need to detain a mentally ill patient who verbalises refusal to consent to treatment. The difficulty comes when deciding to treat a patient who is uncommunicative from a functional or organic mental illness, with medication or ECT. Our common practice is to use the MHA in these patients, even though they have not actually refused treatment.

Having carried out a postal survey of all the consultants in elderly mental illness and their senior registrars in south and west Wales (20 responded out of 22), all agreed with this course of action.

It was brought to our attention by Richard Jones, a leading specialist in Mental Health law, that the criteria for admission under Sections 2 or 3 of the Act cannot be satisfied in respect of a compliant mentally incapacitated patient (i.e. one who is not "persistently and/or purposely" attempting to leave the hospital (see paragraph 19.27 of the Code of Practice; Department of Health \& Welsh Office, 1999, and paragraphs 1$626 \mathrm{~A}$ of the sixth edition of the Mental Health Act Manual; Jones, 1999). Hence, ECT (being a medical treatment for mental disorder) can and should be given to a mentally incapacitated patient under common law as long as the requirements for "treatment of those without capacity to consent" (see paragraph 15.19 of Code of Practice; Department of Health, 1993, and paragraph 15.21 Code of Practice, published 1999) are satisfied.

Perhaps it is significant that this has come to our attention following the Bournewood judgement which clarified our position in treating, under common law, those patients who are compliant but mentally incapacitated. Most would agree that this refers to individuals with learning difficulties or dementia or who are temporarily incapacitated from delirium, and these are indeed specified in paragraph 15.20 of the newly published Code of Practice. It unfortunately does not include such cases as mutism secondary to severe psychotic depression.

We are uncertain how such a widely held practice, which appears to contradict the Code of Practice, originated. We would be interested to hear from anyone who feels they can shed light on this interesting clinical conundrum.

\section{References}

DEPARTMENT OF HEALTH AND WELSH OFFICE (1993) Code of Practice, Mental Health Act 1983. London: HMSO

— \& - (1999) Code of Practice, Mental Health Act 1999. London: The Stationery Office.

JONES, R. M. (1999) Mental Health Act Manual (6th edn). London: Sweet \& Maxwell.

Helen Chubb, Senior Registrar, Delyth Alldrick Consultant Psychiatrist, EMI Directorate, Cardiff \& District Community Healthcare Trust, Whitchurch Hospital, Park Road, Cardiff CF4 7XB

\section{Alternatives to methohexitone}

When the ECT anaesthetic methohexitone was unexpectedly withdrawn earlier this 
จ

columns year we switched to the alternative agent propofol, and very quickly found the expected trends emerging - on average patients have shorter fits, fewer have 'adequate' fits (according to either the motor fit or the electroencephalogram), and in consequence higher stimulus charges were being used as well as routine caffeine augmentation and hyperventilation. Unsurprisingly, our local clinical teams soon began commenting on the increase in the post-ECT confusion.

We have, therefore, begun using thiopentone for those patients who have an unacceptably high seizure threshold with propofol. We have found that thiopentone appears to have noticeably less anticonvulsant effect so that relatively lower charges and longer fits are possible - in one case a $90 \%$ reduction in charge was achieved.

Interestingly, with propofol, a number of patients are responding well even though their fit duration does not meet the usual criteria for 'adequacy' in line with the observations on monitoring seizure activity in the College's ECT Handbook (1995).

We would, therefore, suggest keeping the dose as low as possible if using propofol, to minimise its anticonvulsant effect. If the patient is having short fits it may not be necessary to significantly increase the charge, if feedback from the clinical team indicates the patient is responding well anyway. Thiopentone may be an acceptable alternative for those patients who cannot be given effective treatment using propofol.

A comparison of the last 23 courses of ECT using methohexitone alone with the first 20 not using methohexitone showed $13 / 23$ 'unequivocally good' outcomes in the methohexitone group versus 17/20 in the non-methohexitone group, a nonsignificant trend in favour of 'non-methohexitone' $\left(0.10>P>0.05\right.$ using $\chi^{2}$ with Yates correction)

Thus, the administration of effective ECT is possible without the use of methohexitone.

\section{Reference}

ROYAL COLLEGE OF PSYCHIATRISTS (1995) The ECT Handbook. The Second Report of the Royal College of Psychiatrists Special Committee on ECT. Council Report CR39. London: Royal College of Psychiatrists.

Chris Aldridge, Consultant Psychiatrist, Mandy Assin, Senior Registrar, Safwat Elyas, Honorary Senior House Officer, Brighton General Hospital, Elm Grove, Brighton BN2 3EW

\section{Specialist registrars and responsible medical officer status}

Sir: The Mental Health Act 1983 defines certain duties as being the sole remit of the responsible medical officer (RMO). These include the ability to discharge a section; power to bar discharge of a detained patient by the nearest relative; the granting of Section 17 leave; authorisation of consent to treatment and formulation of aftercare under Section 117 of the Act. The RMO, in relation to a detained patient is "the registered medical practitioner in charge of the treatment of the patient" (Mental Health Act 1983, Section 34(1)). The term 'in charge' is defined in the 1998 Memorandum as meaning "not responsible or accountable for the patients treatment to any other doctor". In the absence of the RMO, such duties are delegated to the acting RMO - usually another consultant covering their colleague's duties.

Can the RMO delegate such tasks to his or her specialist registrar (SpR) during leave of absence? In practice it would appear not, as is the case at present in our trust. However, we argue that delegation should be adopted as best practice. The $\mathrm{SpR}$ is a senior psychiatric trainee, is member of the Royal College of Psychiatrists (having passed the Membership Exam) and is likely to have a better knowledge of the RMO's patients than a consultant colleague nominally deputising. Furthermore, should not a SpR be able to practise, under supervised conditions, the skills of the RMO, the role for which they are training? Indeed, if a SpR covers as a locum consultant, they exercise full RMO powers. It is difficult in our view to understand how training to become a consultant could be considered complete without supervised experience of working with the complexities of the Mental Health Act.

There is support for our proposal in the relevant literature. Jones (1996) discusses the role of the RMO and notes that the medical practitioner need not necessarily have consultant status. The Mental Health Act Memorandum (1998) states that a SpR approved under Section 12(2) can exercise the role of the RMO when the patient's usual doctor is not available and swift action under the Act is required. The new Code of Practice (1999) names the Specialist Registrar as one of those able to grant Section 17 leave in the absence of the RMO, if they are at the time "the doctor in charge of the patient's treatment" (Section 20.3). Indeed, being the doctor 'in charge' of detained patient's treatment at a given time appears to be the key determinant in defining RMO status.

To conclude, we propose that in the absence of a consultant it should be accepted practice that the SpR may practise, under supervised conditions, utilising all the powers allocated by Section 12(2) status and exercising full responsibilities vested in the RMO role. We refer specifically to four areas: (a) Granting of Section 17 leave.

(b) Review of consent to treatment under section.

(c) Discharge of sections, with aftercare planning under Section 117.

(d) Attendance at mental health review tribunals or hospital manager review meetings, to review the section.

We argue that new mental health legislation or guidance should encourage such practice.

\section{References}

DEPARTMENT OF HEALTH (1998) Memorandum on Parts I to VI, VIII and X of the Mental Health Act, 1983. London: The Stationery Office.

— \& WELSH OFFICE (1999) Mental Health Act 1983, Code of Practice. London: The Stationery Office.

JONES, R. (1996) Mental Health Act Manual (5th edn). London: Sweet \& Maxwell.

K. Williams, Specialist Registrar,

R. Macpherson, Consultant Psychiatrist, Severn NHS Trust, Wotton Lawn, Horton Road, Gloucester GL13WL

\section{Retention of psychiatric trainees}

Sir: I was delighted to read Sally Pidd's review regarding the College census and plans to establish an integrated database allowing production of statistics regarding career pathways of psychiatric trainees (Psychiatric Bulletin, October 1999, 23 630-633).

I am interested in the retention of junior psychiatry trainees in the speciality and anecdotally, have been aware throughout my training of the ease with which many good trainees have left without the opportunity to tell their stories. I recently attempted to set up an audit project to identify how many basic level trainees in one teaching hospital scheme went on to pursue psychiatric careers, what became of those who did not and importantly identify the reasons given for leaving using a design method similar to that described by Harvey et al (1998).

Using medical staffing lists I was able to identify that $59 \%(27 / 45)$ of new recruits to the scheme over the years 1988-1990 were members of the Royal College of Psychiatrists 10 years later. Medical staffing lists are destroyed after 10 years and I was, therefore, unable to trace back any further than 1988. Unfortunately, no information was kept on individual doctors other than an initial and surname. It was evident that these handwritten lists were incomplete and inaccurate and made identifying and therefore tracing doctors who had left impossible.

I applaud the College's efforts to collate this type of information and would hope that individual schemes could be involved in auditing their retention of trainees. I 